\title{
Food and Drug Administration Regulation of Food Safety
}

Lawrence O. Gostin

Georgetown University Law Center, gostin@law.georgetown.edu

Katie F. Stewart

Georgetown University Law Center, kfs6@law.georgetown.edu

Georgetown Public Law and Legal Theory Research Paper No. 11-88

This paper can be downloaded free of charge from:

https://scholarship.law.georgetown.edu/facpub/670

http://ssrn.com/abstract $=1865442$

JAMA, June 14, 2011,

http://jama.ama-assn.org/content/early/2011/06/13/jama.2011.885.full.pdf

This open-access article is brought to you by the Georgetown Law Library. Posted with permission of the author. Follow this and additional works at: https://scholarship.law.georgetown.edu/facpub

Part of the Administrative Law Commons, Food and Drug Law Commons, and the Health Law and Policy Commons 


\title{
GEORGETOWN LAW
}

O’Neill Institute for National \&

\section{Global Health Law Scholarship}

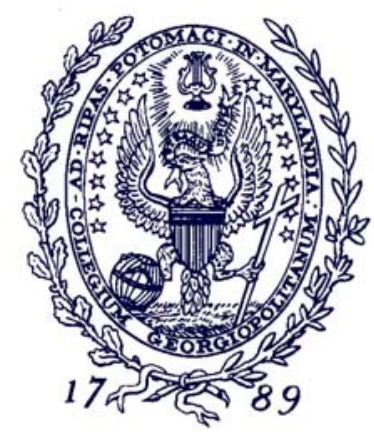

Georgetown Public Law and Legal Theory Research Paper No. 11-88

June 2011

\section{Food and Drug Administration Regulation of Food Safety}

\author{
JAMA, June 14, 2011, \\ http://jama.ama-assn.org/content/early/2011/06/13/jama.2011.885.full.pdf
}

\author{
Katie Stewart \\ Georgetown University Law Center \\ O’Neill Institute for National and Global Health Law \\ kfs6@law.georgetown.edu \\ Lawrence O. Gostin \\ Professor of Law \\ Georgetown University Law Center \\ O’Neill Institute for National and Global Health Law \\ gostin@law.georgetown.edu
}

This paper can be downloaded without charge from:

Scholarly Commons: http://scholarship.law.georgetown.edu/facpub/670/

SSRN: http: / / ssrn.com/abstract $=1865442$ 


\section{Food and Drug Administration Regulation of Food Safety}

Katie Stewart, JD, MPH

Lawrence O. Gostin, JD

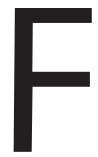

OOD-BORNE ILLNESS REMAINS A MAJOR PUBLIC health challenge in the United States, causing an estimated 48 million illness episodes and 3000 deaths annually. ${ }^{1}$ Despite many triumphs in improving food safety, progress in recent years has stalled, with the incidence of food-borne infection remaining steady during the past decade. ${ }^{1}$ Recent outbreaks linked to spinach, peanut butter, eggs, and the recent Escherichia coli outbreak that originated in Europe have heightened public concern. On January 4, 2011, President Obama signed the FDA Food Safety Modernization Act (FSMA) increasing the US Food and Drug Administration's (FDA's) power to regulate food safety, with a focus on prevention, enhanced recall authority, and oversight of imported food. ${ }^{2}$ The FSMA is a remarkable step forward for the food safety system, affording the FDA much-needed authority. However, the act leaves critical gaps in the regulatory system, including fragmentation among federal agencies, and its potential may be threatened if Congress does not provide sufficient funding to ensure inspections and compliance.

\section{Challenges for Food Safety Regulation}

The fundamental properties of food safety make it difficult to ensure: multiple pathogens from different sources cause food-borne illness; multiple individuals and entities handle food products before they reach end users; and consumers often do not handle food safely. Moreover, data are difficult to collect and analyze due to underreporting. In the United States, these inherent challenges are exacerbated by the magnitude of the national and global food market coupled with flaws in system design.

The vast scope of food production in the United States

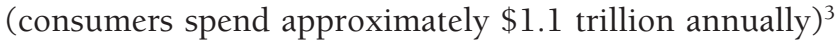
makes regulating the food industry difficult, while also generating powerful political pressure for less burdensome regulation. Equally important is the globalization of food production, with weak regulation in exporting countries. The FDA estimates that $15 \%$ of the US food supply is imported; for some foods, the proportion is much higher (eg, $50 \%$ of fruit and $80 \%$ of seafood). ${ }^{4}$
In addition, food safety regulation is deeply fragmented. Although the FDA and the US Department of Agriculture (USDA) are the primary federal agencies responsible for regulating food, at least 14 different agencies and offices have some responsibility for food safety. ${ }^{5}$ The FDA has broad authority over $80 \%$ of the US food supply, whereas the USDA regulates most meat, poultry, and egg products (but not eggs still in their shells, which are regulated by the FDA). This split often leads to bizarre regulatory results; for example, the FDA is responsible for frozen cheese pizza but the USDA is responsible for frozen pepperoni pizza. Moreover, the Centers for Disease Control and Prevention, as well as state and local health agencies, play a large role in identifying and tracing outbreaks.

\section{FSMA Regulatory Powers}

The FSMA improves prevention, surveillance, and response, and affords the FDA greater powers to safeguard imported food. Overall, the FSMA brings the FDA's food safety practices more in line with core public health tenets and Institute of Medicine recommendations-with emphasis on preventing food contamination rather than reacting after consumers become ill and developing a risk-based framework for inspections and regulation. ${ }^{6}$

Prevention. The FSMA stresses primary prevention at food processing facilities, reducing food-borne illness at its source. Previously, the FDA was highly reactive, responding to food-borne illness after the fact. The FSMA mandates the adoption of preventive control plans and increased inspection frequency for facilities. Of particular importance, it sets risk-based standards for inspection frequency, thereby optimizing the FDA's resources. Prevention will also improve through training, partnerships, and capacity building at the state and local level. In a decentralized food safety system, training will better equip each level of government to prevent, detect, and respond to food-borne illness.

Response. The FSMA strengthens the FDA's ability to detect and respond to food-borne illness, thereby mitigating harm and quelling large outbreaks. It establishes pilot

Author Affiliations: O'Neill Institute for National and Global Health Law, Georgetown University Law Center, Washington, DC.

Corresponding Author: Lawrence O. Gostin, JD, O'Neill Institute for National and Global Health Law, Georgetown University Law Center, 600 New Jersey Ave NW, Washington, DC 20001 (gostin@law.georgetown.edu).

JAMA, Published online June 14, 2011 
projects on food tracing systems, while also improving the surveillance system. Both efforts-tracking food and monitoring illness-give the FDA richer data sources for effective risk-based regulation and inspection.

Recall. One of the FSMA's most heralded reforms is mandatory recall authority. Prior to the FSMA, the FDA did not have the authority to issue mandatory recalls for food, except for infant formula, and instead relied on processors and manufacturers to comply with voluntary recalls. Voluntary compliance slowed response to serious outbreaks and diminished public trust in the food safety system.

Import Safety. Improving the safety of imported food is the final major component of the FSMA. Food production is increasingly international, as consumers seek out-ofseason foods at affordable prices. The globalization of food has exposed US residents to food hazards originating abroad, including the highly publicized melamine contamination of milk products in China. The FSMA adds new checks on imported food, including requiring importers to verify the food safety practices of their suppliers, creating a new certification process for foods deemed to be high risk, and allowing the FDA to inspect foreign facilities. The FSMA also includes capacity building to allow the FDA to assist foreign regulatory agencies.

\section{Enduring Gaps in Food Safety Regulation}

Despite the strengths of its reforms, the FSMA leaves regulatory gaps and no assurance of adequate funding and enforcement. Most obviously, the act does not cover USDAregulated foods, including meat and poultry. Consequently, regulatory fragmentation continues, together with inefficiencies in the USDA regulatory system. Although the FSMA seeks FDA-USDA collaboration in designing certain safety standards, it does not consolidate food safety functions into a single agency as the Government Accountability Office recommended. ${ }^{7}$

Exemptions for small producers present another gap in the food safety system. An amendment to the FSMA, introduced by Sen Jon Tester (D, Montana), exempted small farms from requirements deemed too arduous for small producers. Under the FSMA, a small producer's exemption is lost only after a safety problem has been identified, undermining the act's prevention aims. Although small producers pose different challenges than multinational conglomerates, a robust food safety system requires regulation of all system participants to ensure both public health and public confidence.

Implementation of the law may also fall short of expectations. The act establishes new authorities and enforce- ment, but the FDA's ability to implement ambitious new programs will depend on adequate budget appropriations. Food safety is not an assured priority within a harsh political environment stressing spending restraints and lessburdensome regulation. Other goals, especially stepped-up inspections of foreign facilities, irrespective of funding, require other entities to cooperate with the FDA.

\section{The Future of Food Regulation}

The FSMA fundamentally reforms an antiquated US food safety system and will significantly improve the public's health. Enhancing food safety requires not only effective government regulation, but also advances in regulatory science, industry accountability, and consumer education around safe food handling. In a globalized food environment, improving safety also requires non-US agencies, producers, and importers to meet uniformly high standards.

The FSMA laudably integrates these varied food safety components. Programs to build the capacity of domestic and non-US regulators and producers are essential to a robust food safety system. Yet they risk falling short, particularly because the act does not set firm targets for implementing such programs (unlike provisions setting numeric standards for inspections). Additionally, the FDA should fully engage partners in government and industry to improve global food safety. International cooperation is needed to regulate food contaminants, monitor food safety, and assist developing countries in establishing food safety systems. Through global cooperation, the United States can better ensure safe food for US residents while improving food safety throughout the world.

Published Online: June 14, 2011. doi:10.1001/jama.2011.885 Conflict of Interest Disclosures: All authors have completed and submitted the ICMJE Form for Disclosure of Potential Conflicts of Interest and none were reported.

\section{REFERENCES}

1. Morris JG Jr. How safe is our food? Emerg Infect Dis. 2011;17(1):126-128.

2. FDA Food Safety Modernization Act, Pub L No. 111-353, 124 Stat 3885.

3. USDA Economic Research Service. Food CPI and Expenditures. http://www .ers.usda.gov/Briefing/CPIFoodAndExpenditures. Accessed May 23, 2011.

4. Hamburg M; US Food and Drug Administration. Food Safety Modernization Act: putting the focus on prevention [news release]. http://www.foodsafety.gov /news/fsma.html. Accessed May 23, 2011.

5. Johnson R. The Federal Food Safety System: A Primer. Washington, DC: Congressional Research Service; 2011.

6. Enhancing Food Safety. The Role of the Food and Drug Administration. Washington, DC: Institute of Medicine; 2010.

7. Opportunities to Reduce Potential Duplication in Government Programs, Save Tax Dollars, and Enhance Revenue. Washington, DC: US Government Accountability Office; 2011. GAO-11-318SP. 